\title{
Wear-Fatigue Study of Carbon Steels
}

\author{
Tadeusz Hejwowski ${ }^{1}$, Mirosław Szala ${ }^{{ }^{*}}$ \\ 1 Department of Materials Engineering, Mechanical Engineering Faculty, Lublin University of Technology, \\ Nadbystrzycka 36 Street, 20-618, Lublin, Poland \\ * Corresponding author's email: m.szala@pollub.pl
}

\begin{abstract}
The process of conjoined stress cycling and abrasive or erosive wear is encountered in industry. However, very scant attention has been paid till now to this issue. The paper presents two test rigs designed and built to cope with this experimental problem. Tests were carried out on the range of pure iron (Armco), carbon steels namely S235JR, C45, C70U, C80U, C110U and unalloyed cast steels (L40III, L45III and L50III). Tested iron-based alloys differ in chemical composition, microstructure and Brinell hardness ranging from $80 \mathrm{HB}$ to $350 \mathrm{HB}$. Stress cycling caused strain hardening of ferrite in hypoeutectoid steels and thus reduced their abrasive wear loss. In the hypereutectoid steel stress cycling impaired integrity of the microstructure thus increasing abrasive wear loss. Alternating stresses enhanced ploughing and cutting micromechanisms of erosion. Tensile stress in the tested cast steel had stronger effect on wear loss than the prior stress history.
\end{abstract}

Keywords: abrasive wear, erosive wear, fatigue, carbon steel, cast steel, structural steel, wear, skin hardening steel.

\section{INTRODUCTION}

Wear is a serious problem in industry. It is encountered, for instance, in excavation, earth moving operations, mining industry, power generating systems, gas turbines. The necessity of frequent replacement and reclamation of used parts increases the production costs. It is acknowledged that wear resistance cannot be considered an intrinsic property of material because it depends on wear process type and its parameters The estimated percentage share of various wear processes encountered in industry is [1]: abrasive wear $50 \%$, adhesive wear $15 \%$, erosion $8 \%$, fretting $8 \%$, corrosion $5 \%$ conditions.

Abrasive wear is caused by a movement of hard body over surface of the softer material. Mechanism of abrasive wear include cutting, grooving, fatigue of repeatedly deformed material lips and cracking. Resistance to abrasion is in the first approximation proportional to the hardness of material being abraded. However, more detailed studies showed that abrasion resistance is also influenced by microstructural features of abraded material [2-5].
Erosive wear is frequently caused by the impact of solid particles entrained in a gas or liquid stream. Another form of erosion is caused by the impact of liquid droplets onto material surface [6-8]. The site of solid particle impact experiences high stresses and strains. Local heating of material was also experimentally evidenced. It was revealed in experiments that thin material platelets are extruded, forged and subsequently removed by the next impacting particles. Whereas the subsurface zone, which did not experienced thermal softening, played a role of an anvil [9]. The inadequacy of hardness as a main criterion of material selection was also noticed [10]. Furthermore, no consistent relationship was found between erosion resistance and ultimate or yield strength [11]. The above mentioned material properties are assessed in static tests whereas the erosion process involves multiaxial strain at a very high strain rate. It is acknowledged that erosion intensity depends on a number of factors which can be classified into three main groups: parameters describing solid 
particle motion (such as, for instance, particle velocity, angle of impact), properties of erodent particles (such as their shape, size and hardness) and properties of material being eroded (such as hardness and microstructure) [12].

Wear resistance of materials is most frequently assessed in standard tests which model a particular wear type likewise sliding, abrasion, erosion or corrosion [13-17]. The exception is the fretting wear standard test, in which sliding and corrosion are involved. The wear process caused by simultaneously occurring solid particle erosion and corrosion is termed erosion-corrosion. The process is considered very complex as the current modelling approaches has failed. The conjoined erosion and corrosion processes can produce significantly wear loss than the sum of individual contributions of these processes [18]. Erodent particles remove the already formed layer of corrosion products which results in a continuous exposure of fresh metal surface to the corrosive medium. In turn, corrosion produces surface roughness which facilitates removal of material by impacting particles. Corrosion products are frequently more vulnerable to erosion compared with parent material. Stack [19] developed wear-corrosion maps to distinguish regions, in which particular wear-corrosion mechanisms dominate. The maps are drawn in particle velocity-temperature or particle velocity versus impact angle coordinates. Obviously, the best method is to run the test of monitored exploitation on materials concerned [20].

The effect of residual stress on erosion resistance of material was presented in published works. Deng et al. [21] studied wear resistance of sand blast nozzles made of sintered, laminated $\mathrm{SiC} /(\mathrm{W}, \mathrm{Ti}) \mathrm{C}$ ceramics. The beneficial effect of compressive stresses resulting from a mismatch between thermal expansion coefficients of adjacent layers in the laminated ceramics was found. The effect was rationalized in terms of a counteraction of this stress tensile stresses produced by sand particles impacting onto the nozzle entry. The beneficial effect of compressive residual stress in abrasive wear tested two layered alumina-silicon carbide layered composite was also found [22].

Large compressive stresses are usually found in sputtered coatings. Vierneusel et al. [23] carried out a pin-on-disk experiment on specimens covered with as-sputtered coating and specimens covered with coatings which underwent stress relaxation procedure. It was found that in coatings with high residual stress only a mild wear occurred. It was hypothesized that compressive stress retarded crack nucleation and propagation in the coating.

The effect of externally applied stress on wear was studied in a very few works. Spuzic at al. [24] designed a special test rig to study the effect of stress on abrasive wear. The conventional scratch tester was used to produce single scratches on the surface of the sample which was exposed to fourpoint bending using a specially designed jig. Von der Ohe et al. [25] developed a test rig to study synergy effect between tribocorosion and bending stress. Specimen was exposed to 4-point bending while counter specimen performed reciprocal sliding movement along specimen surface. The test was carried out under electrochemical control. Summing up, the literature survey indicates that the wear-fatigue or erosion-fatigue testing of the ferrous materials is an up-to-date problem which has not been fully understood.

The purpose of this paper was to explore wear-fatigue process of carbon steels and cast steels with various carbon contents. The problem was approached by designing two test rigs to produce the desired stress state in specimen while exposing it to abrasion or erosion.

\section{MATERIAL AND METHODS}

\section{Studied carbon steels and cast irons characterisation}

Tests were carried out on pure iron (Armco), carbon steels namely, S235JR, C45, C70U, C80U, C110U and unalloyed cast steels (L40III, L45III and L50III). Chemical composition of steels and cast steels was measured by means of the optical emission spectrometer Spectromaxx with spark excitation. Chemical composition of tested alloys is listed in Tabs 1 and 2 along with their Brinell hardness. The C70U, C80U, C110U carbon steels belong to skin hardening steels. Lower carbon grades are applied to produce woodworking tools while high carbon grades are used to perform drills, screw dies and screwtaps. The microstructure of C70U consisted of pearlite with small fraction of ferrite, C80U consisted of pearlite while higher carbon grade contained pearlite and secondary cementite. C45 steel was used as a standard in abrasion test. Armco iron containing almost sole ferrite was also included in the study. 
Table 1. Chemical compositions of tested steels, wt. \%

\begin{tabular}{|c|c|c|c|c|c|c|c|c|c|}
\hline \multirow{2}{*}{$\begin{array}{l}\text { Steel } \\
\text { grade }\end{array}$} & \multicolumn{8}{|c|}{ Chemical composition, wt. \% } & \multirow{2}{*}{$\begin{array}{c}\text { Hardness, } \\
\text { HB }\end{array}$} \\
\hline & C & $\mathrm{Mn}$ & $\mathrm{Si}$ & $P$ & $S$ & $\mathrm{Cr}$ & $\mathrm{Ni}$ & $\mathrm{Cu}$ & \\
\hline Armco & 0.02 & 0.06 & 0.005 & 0.005 & 0.02 & 0.005 & 0.02 & 0.01 & 80 \\
\hline S235JR & 0.17 & 0.51 & 0.24 & 0.025 & 0.03 & 0.28 & 0.14 & 0.17 & 130 \\
\hline $\mathrm{C} 45$ & 0.43 & 0.56 & 0.26 & 0.01 & 0.01 & 0.25 & 0.16 & 0.15 & 185 \\
\hline C70U & 0.69 & 0.24 & 0.17 & 0.01 & 0.02 & 0.17 & 0.07 & 0.14 & 260 \\
\hline $\mathrm{C} 80 \mathrm{U}$ & 0.82 & 0.26 & 0.21 & 0.01 & 0.01 & 0.14 & 0.11 & 0.12 & 280 \\
\hline C110U & 1.12 & 0.21 & 0.23 & 0.015 & 0.02 & 0.15 & 0.11 & 0.18 & 350 \\
\hline
\end{tabular}

Table 2. Chemical compositions of tested cast steels, wt. \%

\begin{tabular}{|c|c|c|c|c|c|c|}
\hline \multirow{2}{*}{$\begin{array}{c}\text { Cast steel } \\
\text { grade }\end{array}$} & \multicolumn{5}{|c|}{ Chemical composition, wt.\% } & Brinell \\
\cline { 2 - 7 } & $\mathrm{C}$ & $\mathrm{Mn}$ & $\mathrm{Si}$ & $\mathrm{P}$ & $\mathrm{S}$ & $\begin{array}{c}\text { harndess, } \\
\text { HB }\end{array}$ \\
\hline L40 III & 0.12 & 0.52 & 0.37 & 0.07 & 0.06 & 132 \\
\hline L45 III & 0.23 & 0.67 & 0.42 & 0.05 & 0.05 & 153 \\
\hline L50 III & 0.38 & 0.81 & 0.48 & 0.06 & 0.07 & 171 \\
\hline
\end{tabular}

The tested cast steels belong to the highest grade cast steels. L40III cast steel reveals excellent weldability and because of its magnetic properties it is applied in electrotechnics. The highest carbon cast steel is used when wear resistance is required, however working conditions should not include large impact loads. This steel shows fair weldability. The microstructure of tested cast steels is a mixture of ferrite and pearlite.

\section{Wear-fatigue facilities and experimental}

The considerable effort was put into design and construction of two test facilities. The design of the first tester was based on the already used machine dedicated to test wear loss under steady loads [26]. The tester was rebuild in order to apply alternating stresses to the specimen being worn and to increase the precision of experiments. The tester is presented in Figure 1. The specimen (1) was exposed to four-point bending to induce the desired stress state. The specimen was placed in two pairs of jaws and rested on bars made of hardened steel. To avoid bending of transducer which would have an adverse effect on a precision of readings, the tensometric force sensor (3) was attached to the pair of connecting members these were guided by the linear ball bearings (4). The fixed inner jaw was attached to the machine frame whereas the moving jaw was mounted on the connecting member. The other connecting member was attached via the clutch to the pneumatic actuator (2) of two-sided action. Flow of pressurized air to the pneumatic actuator

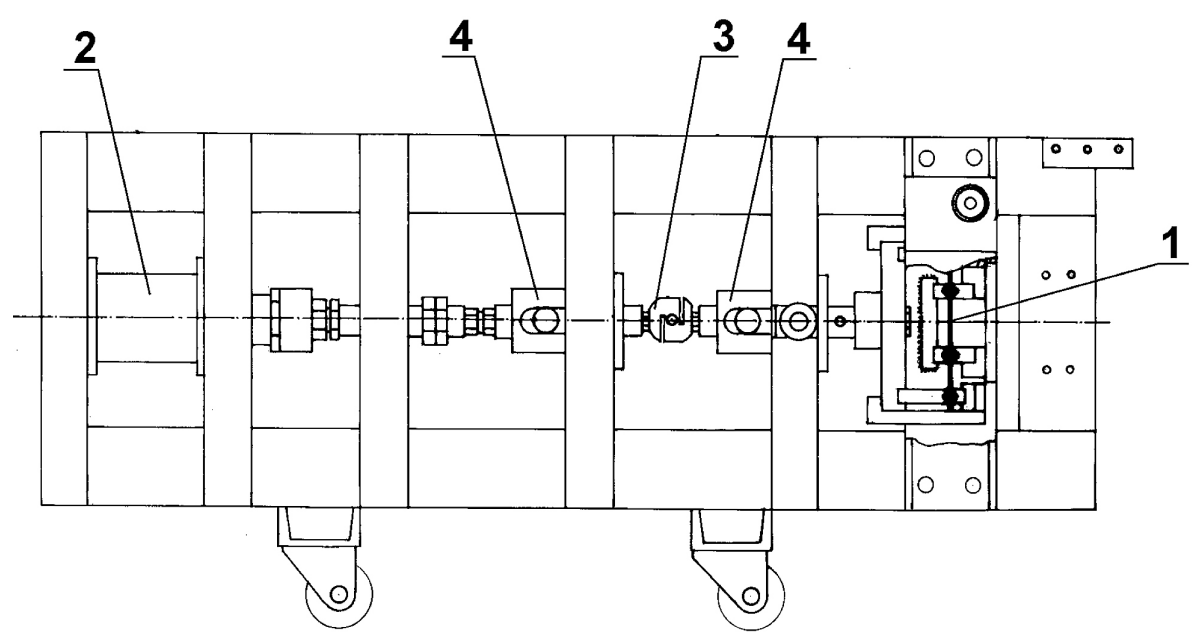

Fig. 1. Scheme of the test rig used to study wear-fatigue process 
was governed by electromagnetic valves which were controlled by the timer unit. The span of the fixed jaw was $75 \mathrm{~mm}$ and that of the moving jaw was $175 \mathrm{~mm}$. The erosion or abrasion test units can be attached to the machine frame.

The test was carried out on flat specimens 200 $\mathrm{mm}$ long, $30 \mathrm{~mm}$ wide and $4 \mathrm{~mm}$ thick. The specimens were made of steels with chemical compositions listed in Table 1. The abrasive used in

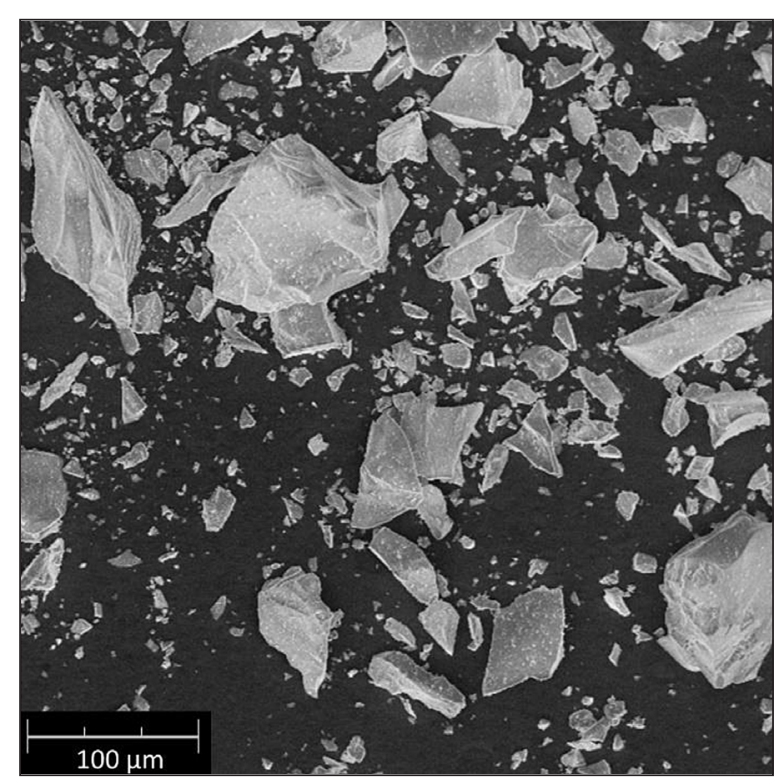

Fig. 2. Silica abrasive used in abrasionfatigue and erosion-fatigue tests wear tests was crushed silica. Abrasive particles were angular in shape, their size was below approximately $100 \mu \mathrm{m}$, as seen in Figure 2. Silica is one of the most prevalent abrasives in industry. It causes severe wear of mining equipment and earth-moving machines. It is acknowledged that angular abrasive particles induce much more abrasive or erosive wear loss compared with spherical ones.

The unit used in the abrasion test is shown in Figure 3. The rubber rimmed roll (2) with $\Phi 50 \times 15 \mathrm{~mm}$ dimensions was used as the counter specimen. The roll was driven by the electric motor (3) mounted on the rotatable arm (4) and pressed to the specimen surface (1) with the force of $20 \mathrm{~N}$. The abrasive was delivered to the friction pair from the abrasive container (6) using the ejector (5) in a stream of argon supplied from the bottle. Angular silica particles become partly embedded in rubber and thus forced to groove the sample. The total time of each abrasion-fatigue test was ten minutes.

In the erosion test (Fig. 4), erodent particles were accelerated by means of pressurized air delivered from a compressor (6) to the nozzle. The position of the nozzle (4) outlet was tracked on the specimen surface using the led diode (7). The specimen (1) was placed in two pairs of jaws $(2,3)$. Abrasive was fed from the abrasive container in the stream

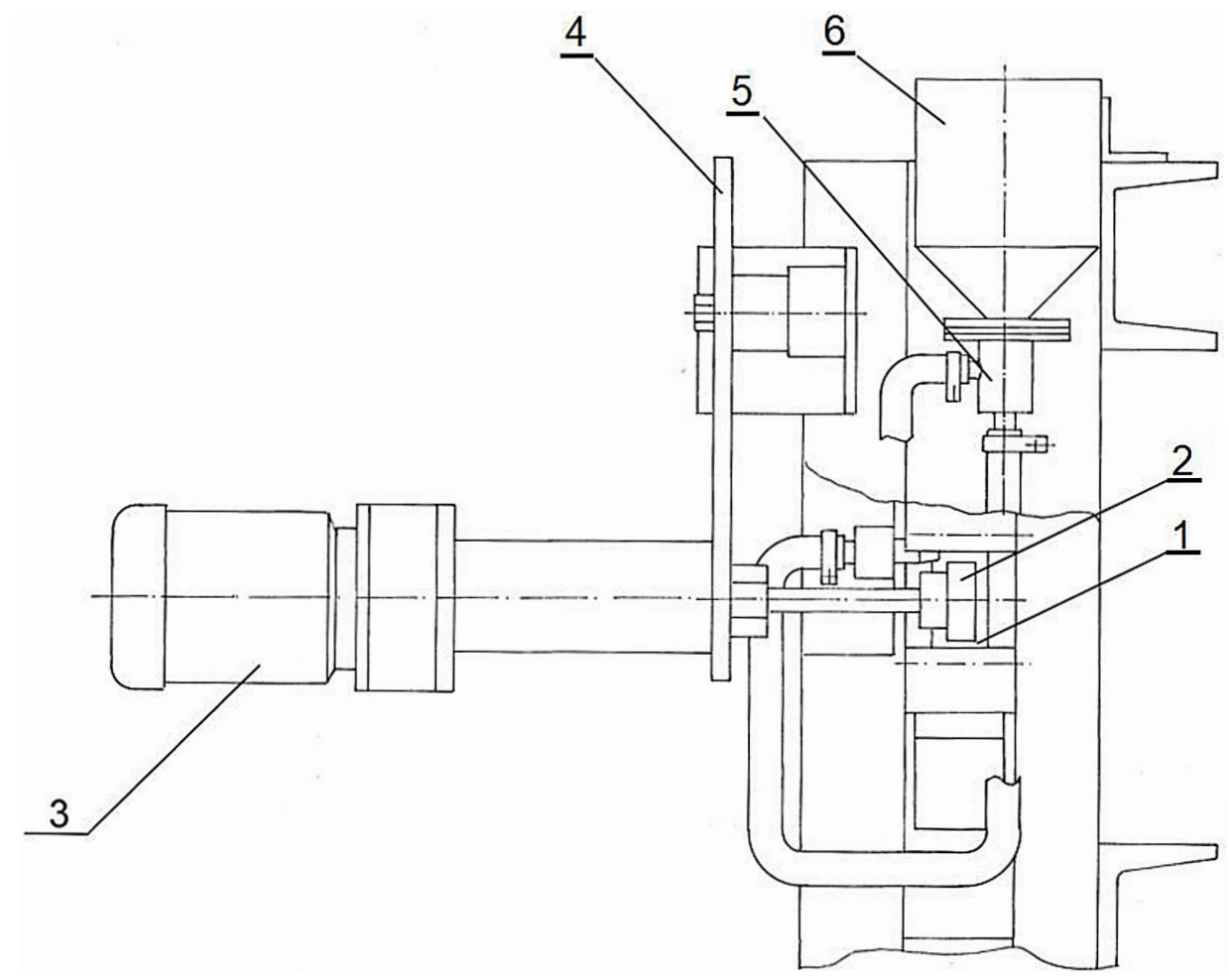

Fig. 3. Scheme of the unit used to conduct abrasion-fatigue test 


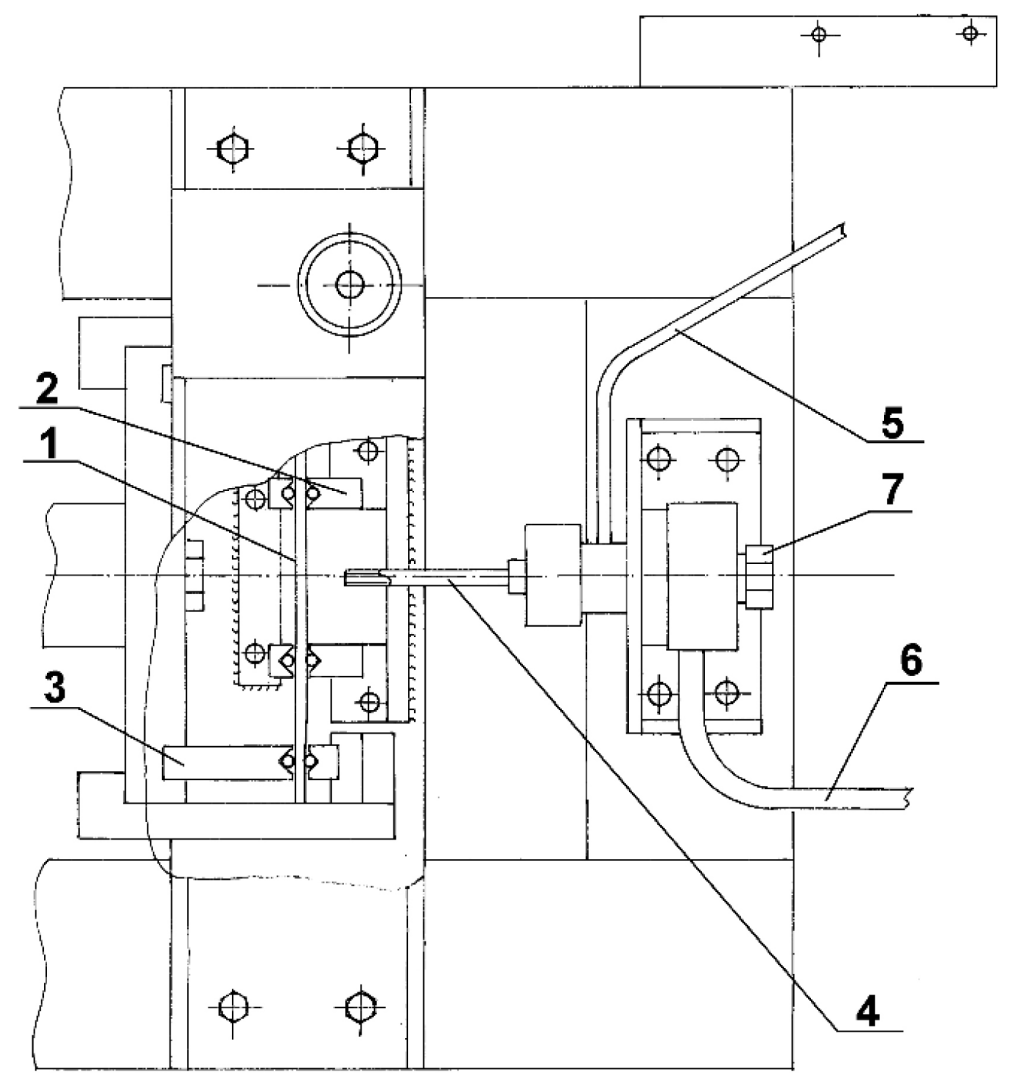

Fig. 4. Scheme of the unit used in erosion-fatigue test
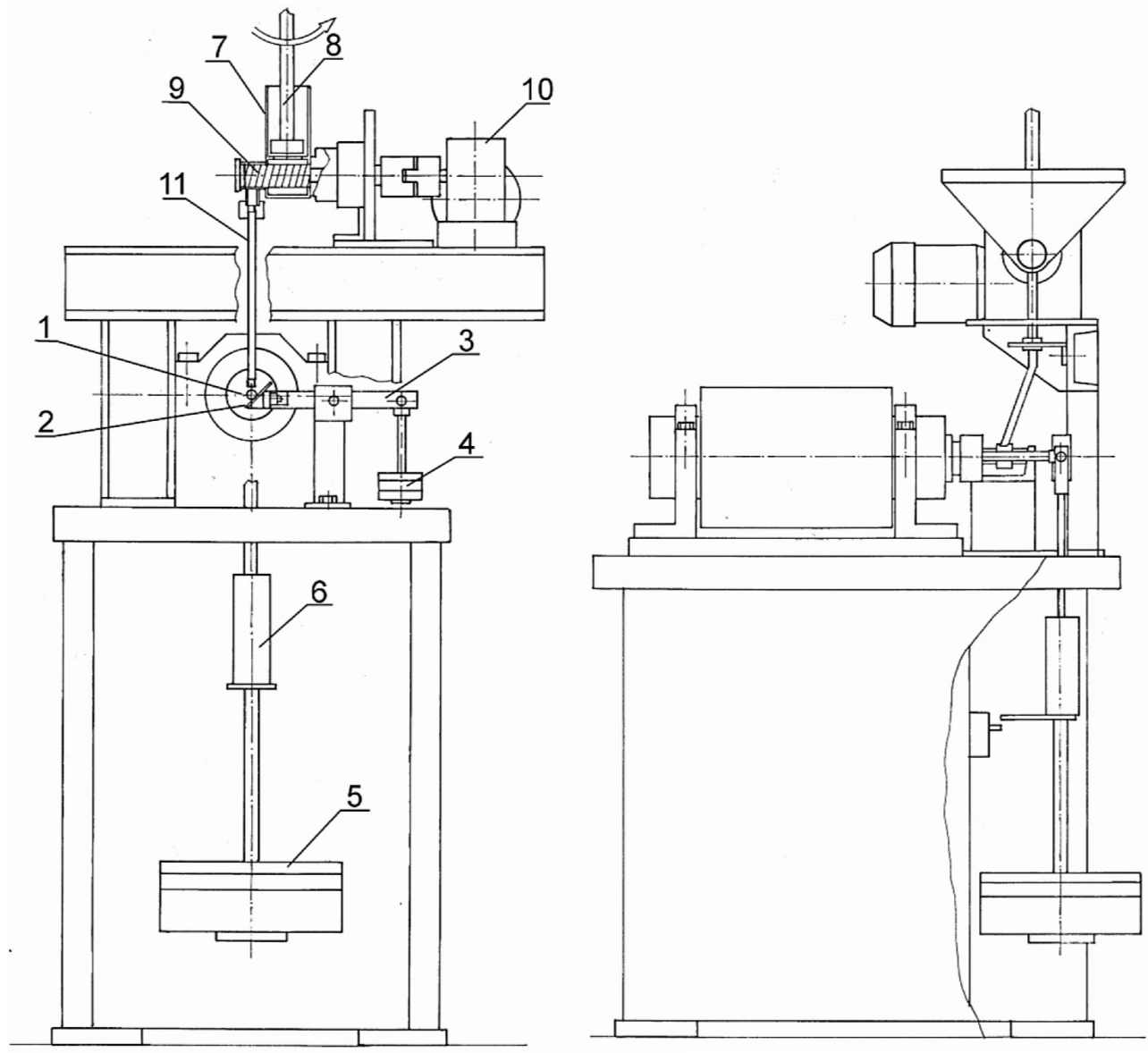

Fig. 5. Scheme of the test rig used to study abrasion-fatigue 


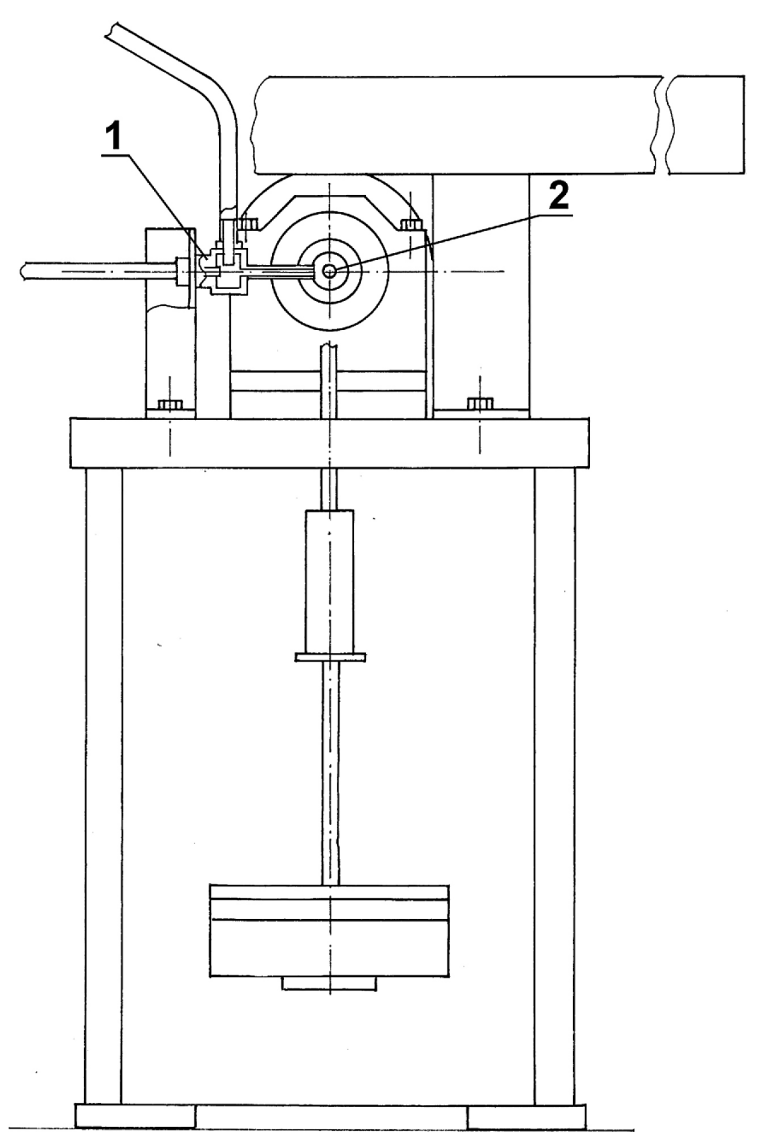

Fig. 6. Scheme of the test rig used to study erosion-fatigue

of argon (6). Particle velocity was $82 \mathrm{~m} / \mathrm{s}$ as determined by the double-disk method [27].

The second test rig was used to study the effect of stress cycles on wear of cast steels which chemical compositions are given in Table 2. The test rig setup used in abrasion testing is shown in Figure 5.

The round $10 \mathrm{~mm}$ in diameter specimen (1) was rigidly attached to the griding spindle, see Figure 5. The spindle was driven by the electric motor. The rotational speed was $3000 \mathrm{rev} . / \mathrm{min}$. as measured by the optical tachometer. The other side of specimen was attached to the rod end with a spherical bearing. Weight (5) was underslung from the rod end through the vibration dumper (6) to impose bending force on specimen. The counter-specimen (2) made of teflon plate with dimensions $30 \mathrm{~mm} \times 30 \mathrm{~mm} \times 8 \mathrm{~mm}$ was fixed on the tip of the articulated lever (3). The other end of the lever was loaded with the dead weight (4). The counter specimen was pressed to the tested specimen with a force of $10 \mathrm{~N}$. The abrasive was delivered form the container (7) equipped with the mixer (8). To provide the uniform abrasive flow, the worm conveyor (9) driven by the electric motor (10) was used. The abrasive was then fed (11) to the friction pair in a stream of argon supplied from the bottle.

The particle jet was either directed perpendicularly to the load force direction or parallelly to it. The test rig setup with the perpendicular orientation of the nozzle is seen in Figure 6. The position of the nozzle (1) exit on the specimen surface (2) was marked with led diode. The erodent plume diameter at a specimen location was a few times higher than specimen diameter. Therefore erosion was caused by abrasive particles impinging onto specimen surface at various angles. Tests on cast steels were performed at stress amplitudes below their fatigue limits. Each test last $10 \mathrm{~min}$. The number of stress cycles for flat specimens was 60 , whereas round specimens experienced 30000 cycles.

Prior to weighting, surface roughness measurements and microscopic investigations, specimens were cleaned with pressurized air to remove dust, cleaned in acetone bath and dried. Mass loss in wear tests was determined using a laboratory balance with $0.1 \mathrm{mg}$ accuracy. To investigate the wear traces of the worn carbon steels and cast steel, the specimens for microscopic investigations were cut. A considerable attention was paid to the cutting process in order to avoid material overheating and deformation. Wear scars were examined by using Phenom ProX Desktop (SEM, Phenom World (Waltham, MA, USA) scanning microscope equipped with an energy dispersive spectroscope and roughness profilometers. Roughness parameters $\left(\mathrm{R}_{\mathrm{a}}\right.$ and $R_{z}$ ) were estimated in the wear trace using Surtronic S-128, Taylor-Hobson, Leicester, UK with according to the ISO 4287 standard [28].

\section{EXPERIMENTAL RESULTS AND DISCUSSION}

Results of wear-fatigue tests are given in Tabs 3-5. Relative abrasion wear is the ratio of mass loss of tested material to the mass loss of C45 steel used as the standard material. Erosion intensity is the ratio of mass loss of tested material to the mass of abrasive spent in the test. Tests on flat specimens were carried out at two stress amplitudes corresponding to low cycle fatigue (LCF) and high cycle fatigue (HCF). It is seen (Table 3) that in hypoeutectoid steels stress cycles reduce abrasive mass loss and increase it for hypereutectoid steel. It is acknowledged that 
in steel, up to carbon content $\mathrm{C}=0.45 \%$, plastic deformation induced by fatigue is confined to ferrite grains. At higher carbon levels plastic deformation is visible in ferrite grain and ferrite lamella forming pearlite [29]. In hypoeutectoid steel ferrite undergoes strain hardening, whereas in C110U steel stress cycles facilitate removal of cementite plates by abrasive particles. Erosion intensity is increased by stress cycling which can be rationalized in terms of Spuzic et al. [24] findings. It was revealed that static tensile stress favours microcutting, while compressive stress facilitates microploughing. Due to heat generation during impact of erodent particle strain hardening does not occur. Worn steel surfaces are shown in the series of Figures 7-11. Studies on surface roughness evolution of carbon steel fatigued under various stress amplitudes covering the range from the infinite life to the low cycle fatigue showed that in all the cases extrusions and intrusions are formed on the surface [30]. It would facilitate material removal in erosion and abrasion tests carried out on specimens exposed to stress cycling prior to wear test. In the wear-fatigue process surface layer is removed in a continuous process. It was evidenced in microstructural examinations of steel fatigued in LCF regime that multiple slips are present in all the grains whereas for HCF plastic deformation occurs only in some grains [31]. In near eutectoid steel tested in LCF regime, dislocations are generated at the ferrite/cementite interface. Stress concentration at interfaces causes cracking of cementite plates [32]. Bulging of cementite plates and their subsequent cracking was seen also in static tensile tests [33].

Abrasion test on cast steel was carried out at low stress amplitude to avoid possible test rig damage on specimen fracture. The abraded material was under compressive stress which reduced abrasion wear. Erosion tests were performed at directions parallel and perpendicular to load direction. For parallel erosion direction, the tested specimen

Table 3. Results of wear-fatigue tests of pure iron and carbon steels

\begin{tabular}{|c|c|c|c|}
\hline Steel & Relative abrasion wear & Erosion intensity, mg/g & Stress amplitude, $\mathrm{MPa}$ \\
\hline \multirow{3}{*}{ Armco } & 1.17 & 0.322 & 0 \\
\hline & 1.15 & 0.376 & 30.9 \\
\hline & 1.12 & 0.360 & 70 \\
\hline \multirow{3}{*}{ S235JR } & 1.17 & 0.320 & 0 \\
\hline & 0.98 & 0.443 & 50 \\
\hline & 0.67 & 0.577 & 140 \\
\hline \multirow{3}{*}{ C45 } & 1.00 & 0.394 & 0 \\
\hline & 0.99 & 0.420 & 85 \\
\hline & 0.95 & 0.434 & 210 \\
\hline \multirow{3}{*}{$\mathrm{C} 70 \mathrm{U}$} & 1.10 & 0.364 & 0 \\
\hline & 1.58 & 0.322 & 120 \\
\hline & 1.22 & 0.390 & 250 \\
\hline \multirow{3}{*}{ C80U } & 0.80 & 0.270 & 0 \\
\hline & 0.88 & 0.447 & 135 \\
\hline & 1.09 & 0.422 & 300 \\
\hline \multirow{3}{*}{ C110U } & 0.53 & 0.377 & 0 \\
\hline & 0.78 & 0.433 & 160 \\
\hline & 1.07 & 0.509 & 330 \\
\hline
\end{tabular}

Table 4. Results of abrasion-fatigue test of cast steels

\begin{tabular}{|c|c|c|}
\hline Cast steel & Mass loss, $\mathrm{g}$ & Stress amplitude, MPa \\
\hline \multirow{2}{*}{ 40LIII } & 0.1291 & 0 \\
\cline { 2 - 3 } & 0.1258 & 116 \\
\hline \multirow{2}{*}{ 45LIII } & 0.1185 & 0 \\
\cline { 2 - 3 } & 0.0843 & 116 \\
\hline \multirow{2}{*}{ 50LIII } & 0.8910 & 116 \\
\cline { 2 - 3 } & 0.8835 & \\
\hline
\end{tabular}


Table 5. Results of erosion-fatigue test of cast steels

\begin{tabular}{|c|c|c|c|}
\hline Cast steel & $\begin{array}{l}\text { Impact direction in relation to } \\
\text { load direction }\end{array}$ & Erosion intensity, mg/g & Stress amplitude, MPa \\
\hline \multirow{6}{*}{ 40LIII } & \multirow{3}{*}{ perpendicular } & 0.2352 & 0 \\
\hline & & 0.2367 & 116 \\
\hline & & 0.2977 & 174 \\
\hline & \multirow{3}{*}{ parallel } & 0.2729 & 0 \\
\hline & & 0.3112 & 116 \\
\hline & & 0.3232 & 139 \\
\hline \multirow{6}{*}{ 45LIII } & \multirow{3}{*}{ perpendicular } & 0.1759 & 0 \\
\hline & & 0.1328 & 116 \\
\hline & & 0.1883 & 197 \\
\hline & \multirow{3}{*}{ parallel } & 0.2188 & 0 \\
\hline & & 0.2270 & 116 \\
\hline & & 0.2838 & 174 \\
\hline \multirow{6}{*}{ 50LIII } & \multirow{3}{*}{ perpendicular } & 0.2311 & 0 \\
\hline & & 0.2551 & 116 \\
\hline & & 0.2873 & 174 \\
\hline & \multirow{3}{*}{ parallel } & 0.2534 & 0 \\
\hline & & 0.2673 & 116 \\
\hline & & 0.2813 & 174 \\
\hline
\end{tabular}

was under tensile stress. Erosion intensity increases with increasing stress amplitude. The erodent plume diameter outside the nozzle was a few times higher compared with specimen diameter. It means that erodent particles impact at various angles onto specimen surface. The shape of the curve erosion intensity versus impact angle depends on the shape of erodent particles [10]. For angular particles, the steep curve with maximum at a tangential angle is expected. It was found in former experiments that abrasive scratches produced on surfaces with a cyclic stressing history are deeper than scratches made on the virgin surface [24]. For perpendicular impact direction, the effect of alternating stress seems poor, tensile stress had stronger influence compared with stressing history.

Figure 7 shows the surface of $\mathrm{C} 45$ steel after abrasion test under low stress. The surface is covered with parallel scratches. In rubber wheel test abrasive particles can roll over the surface of test specimen or groove the material. Grooving is favoured by high applied loads and high harness of abraded material [34]. The test was carried out at relatively low load which accounts for low density of scratches. Deeper scratches were produced in ferrite, points 3 and 4 (chemical compositions: $\mathrm{C}=0 \%, \mathrm{Fe}=96.05 \%, \mathrm{Si}=3.02 \%, \mathrm{Cr}=0.93 \%$ and $\mathrm{C}=0.12 \%, \mathrm{Fe}=92.64 \%, \mathrm{Mn}=1.33 \%, \mathrm{Cr}=1.05 \%$, respectively). Cementite lamella (point 1,
$\mathrm{C}=4.95 \%, \mathrm{Fe}=91.79 \%, \mathrm{Mn}=0.97 \%, \mathrm{Cr}=0.97 \%$, $\mathrm{Si}=1.32 \%$ ) has the even surface. Scratches were stopped at hard obstacles, which were subsequently removed leaving voids behind. Similar pattern was found in abrasion tests carried out in near eutectoid steel, deformation of cementite lamella was also evidenced [35]. In scratch test experiments, a reduction in the interlamellar spacing of pearlite and extrusion of pearlite

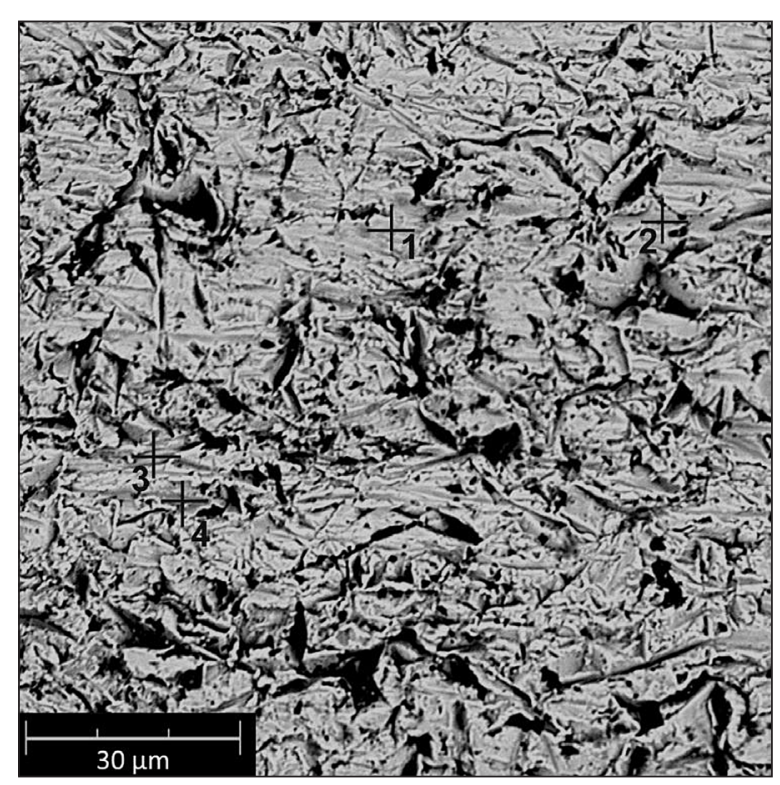

Fig. 7. Surface of C45 steel abraded under low stress amplitude, SEM-EDS 


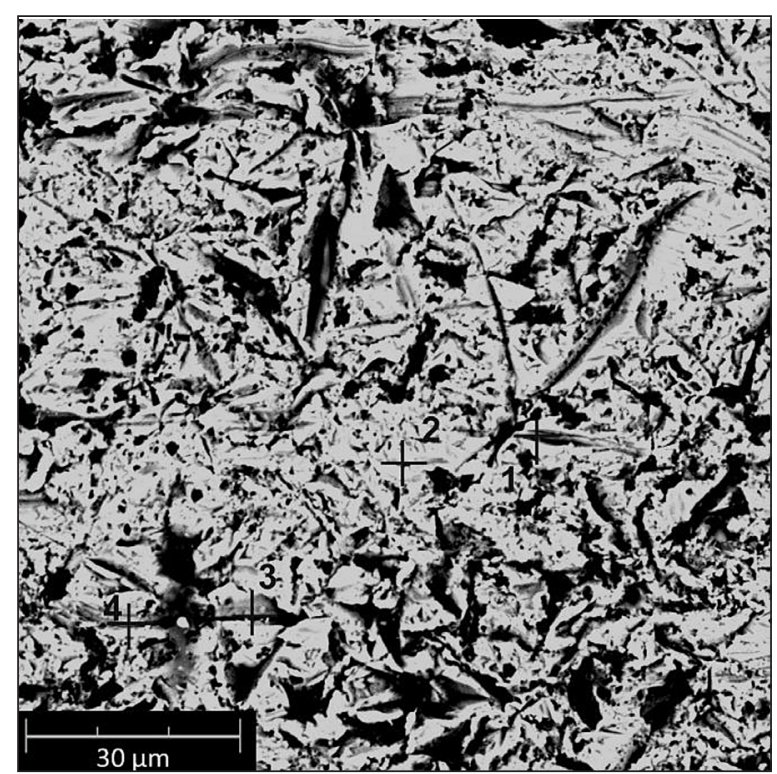

Fig. 8. Surface of C45 steel abraded under high stress amplitude, SEM-EDS

lamellas were also seen $[36,37]$. Ferrite did not provide cementite lamella adequate support during abrasion. In the fatigue study of $\mathrm{C}=0.35$ steel, Kocanda [38] found deformation of ferrite plates in pearlite, bending and fragmentation of cementite lamellas.

Figure 8 shows the surface of $\mathrm{C} 45$ steel abraded under high stress. More surface voids compared with the former picture are seen. Shallow scratches in pearlite are visible. Point 3 is located in ferrite. The scratch is terminated at cementite (4). Chemical composition in points 1 and 2 corresponds to pearlite, $\mathrm{C}=0.64 \%, \mathrm{Fe}=94.85 \%$, $\mathrm{Mn}=1.53 \%, \mathrm{Si}=2.98 \%$ and $\mathrm{C}=0.61 \%, \mathrm{Fe}=95.07 \%$, $\mathrm{Mn}=1.2 \%, \mathrm{Cr}=0.97 \%, \mathrm{Si}=2.15 \%$, respectively.

Figure 9 presents the surface of C45 steel eroded under high stress. Material lips were extruded by the impacting erodent particles. A similar pattern was observed in classic erosion test carried out by McCabe et al. [39]. It is acknowledged that erosion damage of pearlite depends on its orientation relative to the impact direction [40]. Embedded abrasive particles (3) form linear patterns. The squeezed out pearlite lip (2) and the exposed cementite lamella (1) are visible.

Figure 10 shows the surface of $\mathrm{C} 110 \mathrm{U}$ steel after abrasion test carried out under high stress amplitude. It is seen that scratches do not form a parallel pattern. Direction of motion of abrasive particles over the surface is deflected by cementite particles (3 and 7). Deep, wide scratches with plastically deformed edges and narrow scratches which evidence cutting are seen.
Similar pattern was found in the abrasion test on near eutectoid steel [40]. Plates of cementite protrude from the surface $(1,2,4,5)$. Abrasive particle located in the void left by removed cementite particle is seen (point $6, \mathrm{Si}=27.03 \%$, $\mathrm{Fe}=52 \%, \mathrm{O}=20.97 \%$ ). Strains induced by fatigue cycles were essentially confined to ferrite plate, secondary cementite lamellas are forward extruded and thus exposed to wear process.

Figure 11 presents the surface of $\mathrm{C} 110 \mathrm{U}$ steel eroded under high stress. Numerous erodent particles embedded in the surface are seen (spot 3 in

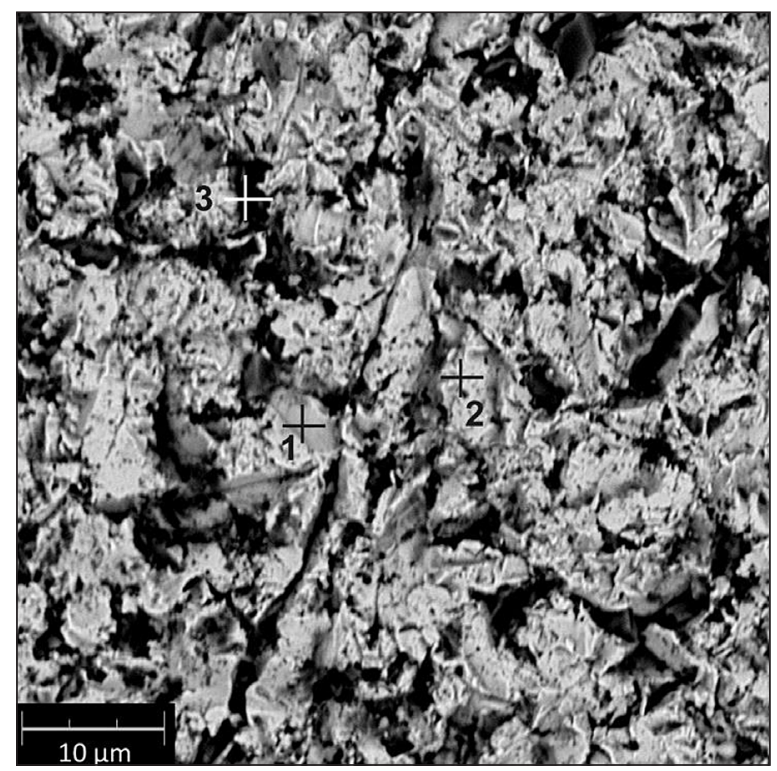

Fig. 9. Surface of C45 steel eroded under high stress amplitude, SEM-EDS

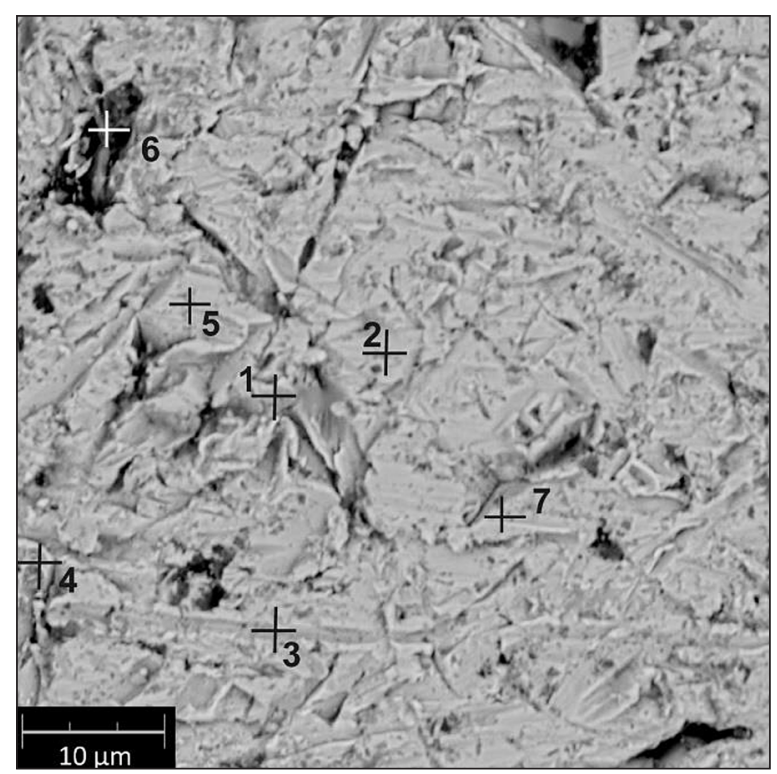

Fig. 10. Surface of C110U steel after abrasion under high stress amplitude, SEM-EDS 


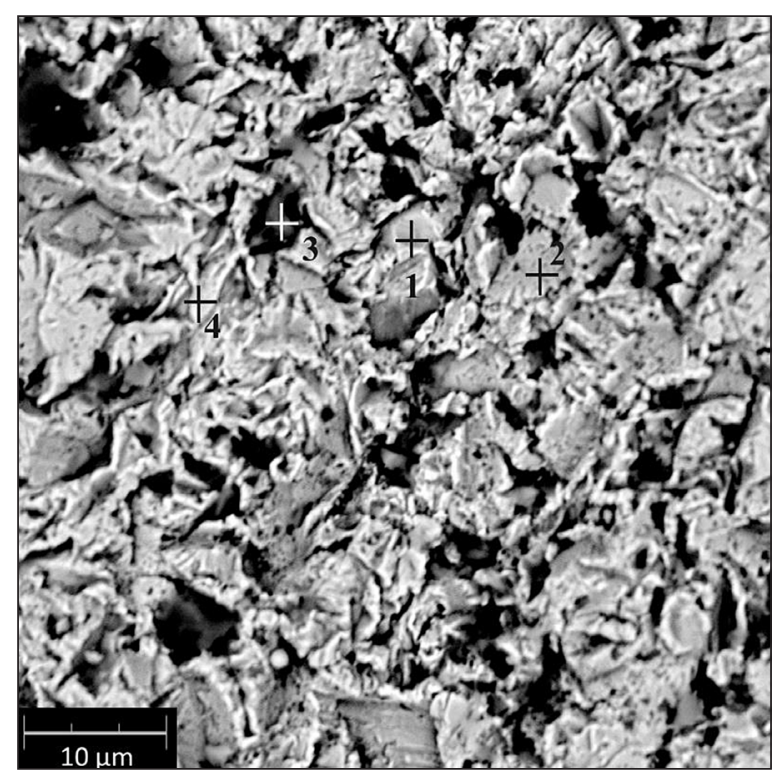

Fig. 11. C110U steel eroded under high stress amplitude, SEM-EDS

Fig. 11). The extruded ferrite lip (point 2, $\mathrm{C}=0 \%$, $\mathrm{Fe}=97.61 \%, \mathrm{Mn}=0.49 \%, \mathrm{Cr}=0.37 \%, \mathrm{Si}=1.52 \%$,), cementite particle protruding from the surface (point $1, \mathrm{C}=6.76 \%, \mathrm{Fe}=92.34 \%, \mathrm{Si}=0.9 \%$ ) and deformed pearlite are seen. Embedded erodent particles act as a reinforcement of the surface thus increasing its wear resistance. However, next erodent particles on impact onto the embedded particle can be reflected in the direction tangent to the surface thus causing erosion by the cutting mechanism $[41,42]$. Resistance of pearlite to erosion depends on the orientation of pearlite plates relative to the impingement direction of erodent particles. The highest resistance reveal pearlite plates oriented perpendicularly to striking particle [42, 43]. Ye et al. [44] carried out microhardness measurements on carbon steel specimens which were fatigued in HCF regime prior to test. It was found that pearlite hardness remained almost independent on stress amplitude except for very high number of cycles close to fatigue fracture. In contrast, microhardness of ferrite revealed a transient behaviour and it increased with increasing number of cycles and then gradually decreased with further increase in a number of cycles. It should be mentioned, that the tests presented in the paper were carried out at much lower number of cycles. Furthermore, it was found that $\mathrm{R}_{\mathrm{a}}$ and $\mathrm{R}_{\mathrm{z}}$ parameters were higher for abrasion compared with erosion. The noteworthy finding is that both parameters go through minima for the eutectoid steel. The highest roughness parameters were observed for Armco iron, for stress amplitude corresponding to $\mathrm{LCF}$ and the abrasion test, $\mathrm{R}_{\mathrm{a}}=1.83$ $\mu \mathrm{m}$ and $\mathrm{R}_{\mathrm{z}}=11.29 \mu \mathrm{m}$. For C110U steel $\mathrm{R}_{\mathrm{a}}=1.72$ $\mu \mathrm{m}$ and $\mathrm{R}_{\mathrm{z}}=10.91 \mu \mathrm{m}$. It testifies that in wear of hypoeutectoid steel the leading process is ferrite removal. For the hypereutectoid steel, plates of secondary cementite during stress cycling are forward extruded and thus devoid of adequate support and vulnerable to abrasion or erosion.

\section{SUMMARY}

The paper presents results of a pioneering study into the effect of alternating stresses on abrasive and erosive wear. Two test rigs were designed and built to approach this problem. Test were carried out on a wide range of carbon steels and cast steels with different carbon content, microstructure and hardness. For hypoeutectoid steel stress cycling causes strain hardening thus reducing abrasive wear loss. In $\mathrm{C} 110 \mathrm{U}$ steel stress cycles impair integrity of microstructural constituents which considerably increases wear loss. Alternating stresses increased erosion intensity of all tested steels which can be explained by the fact that in successive stress half cycles two basic erosion micromechanisms i.e. cutting and ploughing are alternatively enhanced. It was found in the erosion-fatigue test on cast steels that tensile stress had stronger effect on wear loss than prior stress history.

\section{Acknowledgement}

The research was financed in the framework of Individual Grant no. FD-20/IM-5/043 funded by Scientific Board Discipline of Mechanical Engineering, Lublin University of Technology, Poland.

\section{REFERENCES}

1. Eyre T.S. Wear characteristics of metals. Tribology International. 1976;9(5):203-12.

2. Hejwowski T., Weroński A. Studies on the extension of the service life of large industrial fans. Journal of Materials Processing Technology. 1995;54(1):144-8.

3. Łatka L., Szala M., Macek W., Branco R. Mechanical Properties and Sliding Wear Resistance of Suspension Plasma Sprayed YSZ Coatings. Adv Sci Technol Res J. 2020;14(4):307-14.

4. Hejwowski T. Erosive and abrasive wear resistance of overlay coatings. Vacuum. 2008;83(1):166-70. 
5. Szala M., Szafran M., Macek W., Marchenko S., Hejwowski T. Abrasion Resistance of S235, S355, C45, AISI 304 and Hardox 500 Steels with Usage of Garnet, Corundum and Carborundum Abrasives. Adv Sci Technol Res J. 2019;13(4):151-161.

6. Singh J., Singh S., Pal Singh J. Investigation on wall thickness reduction of hydropower pipeline underwent to erosion-corrosion process. Engineering Failure Analysis. 2021;127:105504.

7. Szala M., Świetlicki A., Sofińska-Chmiel W. Cavitation erosion of electrostatic spray polyester coatings with different surface finish. Bulletin of the Polish Academy of Sciences: Technical Sciences. 2021;69(4):e137519

8. Verna E., Biagi R., Kazasidis M., Galetto M., Bemporad E., Lupoi R. Modeling of Erosion Response of Cold-Sprayed In718-Ni Composite Coating Using Full Factorial Design. Coatings. 2020;10(4):335.

9. Levy A.V. The platelet mechanism of erosion of ductile metals. Wear. 1986;108(1):1-21.

10. Kleis I., Kulu P. Solid Particle Erosion: Occurrence, Prediction and Control. London: SpringerVerlag; 2008.

11. Sundararajan G. The solid particle erosion of metallic materials: The rationalization of the influence of material variables. Wear. 1995;186-187:129-44.

12. Stachowiak G., Batchelor A.W. Engineering Tribology. 4 edition. Butterworth-Heinemann; 2016;884.

13. Wojtacha A., Kciuk M., Opiela M. Effect of Heat Treatment Conditions on Corrosion Resistance of $0.28 \mathrm{C}-1.4 \mathrm{Mn}-0.3 \mathrm{Si}-0.26 \mathrm{Cr}$ Steel with $\mathrm{Nb}$, Ti, and V Microadditions. Materials. 2021;14(12):3254.

14. Walczak M., Pieniak D., Niewczas A.M. Effect of recasting on the useful properties CoCrMoW alloy. Eksploatacja i Niezawodnosc - Maintenance and Reliability. 2014;16(2):330-336.

15. Tomków J., Czupryński A., Fydrych D. The Abrasive Wear Resistance of Coatings Manufactured on High-Strength Low-Alloy (HSLA) Offshore Steel in Wet Welding Conditions. Coatings. 2020;10(3):219.

16. Łatka L., Michalak M., Szala M., Walczak M., Sokołowski P., Ambroziak A. Influence of $13 \mathrm{wt} \%$ $\mathrm{TiO} 2$ content in alumina-titania powders on microstructure, sliding wear and cavitation erosion resistance of APS sprayed coatings. Surface and Coatings Technology. 2021;410:126979.

17. Czupryński A. Flame Spraying of Aluminum Coatings Reinforced with Particles of Carbonaceous Materials as an Alternative for Laser Cladding Technologies. Materials. 2019;12(21):3467.

18. Rajahram S.S., Harvey T.J., Walker J.C., Wang S.C., Wood R.J.K. Investigation of erosion-corrosion mechanisms of UNS S31603 using FIB and TEM. Tribology International. 2012;1(46):161-73.
19. Stack M.M., Pungwiwat N. Erosion-corrosion mapping of $\mathrm{Fe}$ in aqueous slurries: some views on a new rationale for defining the erosion-corrosion interaction. Wear. 2004;256(5):565-76.

20. Hejwowski T., Gała Z., Drzeniek H. Erosive and corrosive wear resistance of arc sprayed coatings on pipes of superheaters of the third stage of a boiler of a heat and power generating plant. Welding Technology Review. 2009;81(9):81-5.

21. Deng J., Liu L., Ding M. Effect of residual stresses on the erosion wear of laminated ceramic nozzles. Materials Characterization. 2008;59(1):1-8.

22. Dancer C.E.J., Yahya N.A., Berndt T., Todd R.I., de Portu G. Effect of residual compressive surface stress on severe wear of alumina-silicon carbide two-layered composites. Tribology International. 2014;74:87-92.

23. Vierneusel B., Benker L., Tremmel S., Göken M., Merle B. Isolating the effect of residual stresses on coating wear by a mechanical stress relaxation technique. Thin Solid Films. 2017;638:159-166.

24. Spuzic S., Strafford K.N., Subramanian C., Green L. Influence of stress state on abrasive wear of steels. Wear. 1995;184(1):83-86.

25. Von der Ohe C.B., Johnsen R., Espallargas N. A multi-degradation test rig for studying the synergy effects of tribocorrosion interacting with 4-point static and cyclic bending. Wear. 2011;271(11):2978-2990.

26. Weroński A., Hejwowski T. Effect of stress on abrasive and erosive wear of steels and sprayed coatings. Vacuum. 2008;83(1):229-233.

27. Ruff A.W., Ives L.K. Measurement of solid particle velocity in erosive wear. Wear. 1975;35(1):195-9.

28. ISO 4287:1997. Geometrical Product Specifications (GPS) - Surface texture: Profile method Terms, definitions and surface texture parameters. Geneva, Switzerland: International Organization for Standardization.

29. Subramanya Sarma V., Padmanabhan K.A. Low cycle fatigue behaviour of a medium carbon microalloyed steel. International Journal of Fatigue. 1997;19(2):135-40.

30. De Lacerda J.C., Martins G.D., Signoretti V.T., Teixeira R.L.P. Evolution of the surface roughness of a low carbon steel subjected to fatigue. International Journal of Fatigue. 2017;102:143-148.

31. Lukáš P., Kunz L. Specific features of high-cycle and ultra-high-cycle fatigue. Fatigue \& Fracture of Engineering Materials \& Structures. 2002;25(89):747-53.

32. Adamczyk-Cieślak B., Koralnik M., Kuziak R., Brynk T., Zygmunt T., Mizera J. Low-cycle fatigue behaviour and microstructural evolution of pearlitic and bainitic steels. Materials Science and Engineering: A. 2019;747:144-53. 
33. Zhao Y., Tan Y., Ji X., Xiang Z., He Y., Xiang S. In situ study of cementite deformation and its fracture mechanism in pearlitic steels. Materials Science and Engineering A, Structural Materials: Properties, Microstructure and Processing. 2018;731:93-101.

34. Nahvi S.M., Shipway P.H., McCartney D.G. Particle motion and modes of wear in the dry sand-rubber wheel abrasion test. Wear. 2009;267(11):2083-2091.

35. Das Bakshi S., Shipway P.H., Bhadeshia H.K.D.H. Three-body abrasive wear of fine pearlite, nanostructured bainite and martensite. Wear. 2013;308(1):46-53.

36. Pereira J.I., Tressia G., Machado P.C., Franco L.A., Sinatora A. Scratch test of pearlitic steels: Influence of normal load and number of passes on the sub-superficial layer formation. Tribology International. 2018;128:337-348.

37. Pereira J.I., Tressia G., Machado P.C., Sinatora A., Souza R.M. Multi-pass scratch test on pearlitic steel: Phase identification and crystallographic orientation analysis of the sub-surface layers. Wear. 2021;472-473:203625.

38. Kocanda S. Fatigue Failure of Metals. Alphen aan den Rijn: Springer Netherlands; 1978. (Fatigue and Fracture).
39. McCabe L.P, Sargent A.G., Conrad H. Effect of microstructure on the erosion of steel by solid particles. Wear. 1985;105(3):257-277.

40. Modi O.P., Mondal D.P., Prasad B.K., Singh M., Khaira H.K. Abrasive wear behaviour of a high carbon steel: effects of microstructure and experimental parameters and correlation with mechanical properties. Materials Science and Engineering: A. 2003;343(1):235-42.

41. Okonkwo P.C. Influence Of Particle Velocities And Impact Angles On The Erosion Mechanisms Of AISI 1018 Steel. AML. 2015;6(7):653-9.

42. Islam M.D.A., Alam T., Farhat Z.N., Mohamed A., Alfantazi A. Effect of microstructure on the erosion behavior of carbon steel. Wear. 2015;332333:1080-9.

43. Javaheri V., Porter D., Kuokkala V.T. Slurry erosion of steel - Review of tests, mechanisms and materials. Wear. 2018;408-409:248-73.

44. Ye D., Tong X., Yao L., Yin X. Fatigue hardening/ softening behaviour investigated through Vickers microhardness measurement during highcycle fatigue. Materials Chemistry and Physics. 1998;56(3):199-204. 